\title{
Calcium chloride linked camel milk derived casein nanoparticles for the delivery of sorafenib in hepatocarcinoma cells
}

\author{
Aastha MitTaL ${ }^{1}$; Neelam MaHala ${ }^{1}$; Kowthavarapu Venkata KRISHNA ${ }^{2}$; Uma S. DUbeY ${ }^{1, *}$; Sunil Kumar DUbeY ${ }^{2,3, *}$ \\ ${ }^{1}$ Department of Biological Sciences, Birla Institute of Technology and Science, Pilani Campus, Pilani (BITS-PILANI), 333031, India \\ 2 Department of Pharmacy, Birla Institute of Technology and Science, Pilani Campus, Pilani (BITS-PILANI), 333031, India \\ ${ }^{3}$ R\&D Healthcare Division Emami, Ltd., Kolkata, 700056, India
}

Key words: Camel milk derived casein nanoparticles, Sorafenib, UV spectroscopy, FTIR, HepG2 cells, Apoptosis

\begin{abstract}
Sorafenib, a multikinase inhibitor used for the treatment of hepatocellular carcinoma, is limited by its low oral bioavailability. To overcome this drawback, we have developed novel camel milk casein-derived nanoparticles as a drug delivery system. Camel milk casein is not only biocompatible on oral administration but is actually a dietary protein of pharmaceutical relevance. Casein is used because of its amphiphilic nature, self-assembling property, ability to show sustained release, and capability of encapsulating both hydrophilic and hydrophobic drugs. In this study, camel milk casein nanoparticles loaded with sorafenib were developed and characterized. Characterization of casein nanoparticles was done by dynamic light scattering (DLS), zeta potential analysis, scanning light microscopy (SEM), and FTIR. The drug content in nanoparticle and drug-protein binding studies were conducted by UV spectroscopy. The cytotoxicity and cellular uptake efficiency studies were performed in HepG2 cell lines. It was observed that the cytotoxic effect of sorafenib loaded camel milk casein nanoparticles was more than free sorafenib in HepG2 cells. This work suggests camel milk casein as a suitable drug delivery molecule for sorafenib. In the future, it may also be used in enhancing the efficacy and specific distribution of other water-insoluble anticancer drugs.
\end{abstract}

\section{Introduction}

Nanotechnology has a very high potential in the diagnosis, treatment, and management of cancer (Gmeiner and Ghosh, 2015; Din et al., 2017). The characteristics properties of nanoparticles (NPs) like small size, customized surface, improved solubility, multi-functionality, and administration through different routes are of utmost importance (Krishna et al., 2019). These features overcome the disadvantages of using conventional chemotherapeutic agents (Singh and Lillard, 2009; Patra et al., 2018; Hejmady et al., 2020). Different nanocarriers such as liposomes, micelles, polymeric nanomaterials, mesoporous silica, metallic nanoparticles have been used in drug delivery for improving an array of biomedical applications (Krishna et al., 2020). Among various kinds of protein NPs, milk whey proteins, alpha-lactalbumin, $\beta$-lactoglobulin, caseins, etc., have been investigated for the delivery of drugs, nutraceuticals, and bioactive peptides. These GRAS natural derivatives have characteristics like

${ }^{\star}$ Address correspondence to: Sunil Kumar Dubey,

sunilbit2014@gmail.com; Uma S. Dubey, uma@pilani.bits-pilani.ac.in Received: 24 January 2021; Accepted: 29 March 2021 biocompatibility, amphiphilicity, wide availability, lack of toxicity, non-antigenicity, and low cost, making them suitable for drug delivery, safety, and improved therapeutic potential of anticancer drugs (Lohcharoenkal et al., 2014).

Casein nanoparticles have a high drug loading capacity and are able to deliver both hydrophilic and hydrophobic drug molecules. The pH-dependent behavior of casein micelles makes it beneficial for the controlled release of substances administered orally. Furthermore, the unfolded structure of caseins makes them easily accessible for proteolysis, ensuring good release by proteolytic enzymes in the gastrointestinal tract. Additionally, caseins can penetrate the cell membrane in an energy-independent fashion, which can enhance cellular uptake on oral administration. Physiological degradation products of casein produce immunomodulatory peptides, antioxidants, and ACE inhibitors (which optimize blood pressure regulation). All of these features make casein a promising candidate for encapsulation matrix for anticancer drugs (Głąb and Boratyński, 2017; Sahu et al., 2008).

Camel milk has been traditionally consumed worldwide for its nutritional benefits and medicinal properties. It also has therapeutic and prophylactic benefits against cancer (Dubey et al., 2016; Al haj and Al Kanhal, 2010). Camel 
milk proteins have more thermostability and $\mathrm{pH}$ hydrolysis resistance (Atri et al., 2011). Camel milk casein is present in the micellar form, is easily biodegradable, has an amphiphilic character, is an antioxidant, and has a molecular chaperone-like activity (Kumar et al., 2016). Earlier, also camel casein has been used as an effective nano vehicle for curcumin, and its application has been suggested in functional health food formulations (Esmaili et al., 2011). Camel milk casein has the potential to bind with both polar and non-polar compounds and serve as a suitable nanocarrier for other physiological compounds, including drugs. Therefore, in our study, we have synthesized camel milk casein nanoparticles and used them as a carrier for encapsulating the drug sorafenib, which is an FDAapproved drug against human hepatocellular carcinoma (HCC). HCC is the most common type of primary liver cancer and the most common cause of death in people with cirrhosis (Balogh et al., 2016).

Kinases play a very important role in tumor cell signaling, angiogenesis, and apoptosis (Krishna et al., 2021). Sorafenib is a very promising anticancer drug with the properties of a multikinase inhibitor. It acts against several solid tumors by preventing cell proliferation, tumor growth, and angiogenesis (Jindal et al., 2019). However, sorafenib is a small-molecule drug, having poor aqueous solubility leading to low bioavailability. As it is a small-molecule drug, it may distribute throughout the whole body and be rapidly metabolized in the body leading to adverse effects (Babos et al., 2018). Camel milk is known to reduce drug-induced hepatic and renal toxicity, whereas casein-derived peptides are important pharmaceutically active molecules in addition to being immunomodulatory molecules (Głąb and Boratyński, 2017; Kumar et al., 2016). Therefore, in this study, we have explored the use of casein-derived nanoparticles from camel milk for the encapsulation of sorafenib. For this, we have initially developed and characterized camel casein nanoparticles. Later we studied the cellular uptake and cytotoxicity of sorafenib loaded casein nanoparticles in the HepG2 cell line.

\section{Materials and Methods}

Chemicals and reagents

SDS-PAGE molecular weight marker, MTT (3-(4,5dimethylthiazol-2-yl)-2,5-diphenyltetrazolium Bromide, DAPI (4',6-diamidino-2-phenylindole) were purchased from Sigma (Bangalore, India), 2-Benzothiazolyl)-7-(diethylamino) coumarin (C6) was purchased from TCI Chemicals (India) Pvt. Ltd. All organic solvents were of HPLC grade.

\section{Camel milk sample collection}

Camel milk samples were collected from 'Sarika Raika Milk Bhandar', Jaipur, India. The sample was collected under aseptic conditions, stored at $-20^{\circ} \mathrm{C}$ in a sterile container until further use.

Isolation and purification of casein protein from camel milk Isolation of casein from camel (Camelus dromedarius) milk as was done according to the process described earlier (Salami et al., 2011; Kumar et al., 2016) with slight modification. Briefly, fat was removed from the milk by centrifugation at $8000 \mathrm{rpm}$ for
$30 \mathrm{~min}$ at $4^{\circ} \mathrm{C}$. The supernatant containing skimmed milk was collected for further use. Whey and casein were separated by acid precipitation with $1 \mathrm{~N} \mathrm{HCl}$ at $\mathrm{pH} 4.6$ and centrifugation at $12000 \mathrm{rpm}$ for $30 \mathrm{~min}$ at $4^{\circ} \mathrm{C}$. The precipitated casein was washed thrice with distilled water. The precipitated casein pellet was kept at $-20^{\circ} \mathrm{C}$ until further use and solubilized according to a reported method (Madadlou et al., 2009) briefly described as follows. Casein solution (5\%) was prepared by adding $10 \mathrm{~g}$ casein protein to $200 \mathrm{~mL}$ of deionized water ( $\mathrm{pH} 7.0$ ), stirring at $1000 \mathrm{rpm}$ for $60 \mathrm{~min}$ at room temperature, sodium azide $(0.03 \%)$ was added to prevent any microbial contamination. The solution was stored at $4^{\circ} \mathrm{C}$ for $10-12 \mathrm{~h}$ to allow complete hydration. The $\mathrm{pH}$ of the solution, which was originally 6.48 , was then adjusted to 7,9 , or 12 , separately, by slow addition of $1 \mathrm{~N}$ sodium hydroxide solution with constant stirring.

\section{Polyacrylamide gel electrophoresis}

Skimmed milk and isolated camel milk casein protein were analyzed by SDS-PAGE on $12 \%$ gel under reducing condition by using a Bio-Rad mini gel electrophoresis unit run at $80 \mathrm{~V}$. Before the electrophoresis, skimmed milk and casein protein samples were diluted to $2 \mu \mathrm{g} / \mu \mathrm{L}$ with the sample buffer. Sample denaturation was done for $5 \mathrm{~min}$ at $100^{\circ} \mathrm{C}$, and protein samples were loaded to each well. Proteins in gel were stained by Coomassie Brilliant Blue $\mathrm{R}-250$, and the gel image was viewed by the use of a gel documentation system (BioRad). Separated proteins were validated for identification using the molecular weight marker.

\section{UV visible spectroscopy}

Quantitative analysis of sorafenib and casein was performed by UV spectroscopy. Stock solutions of casein and sorafenib drug were prepared in MQ water and methanol, respectively. The UV absorption spectra were recorded on a UV-2700 spectrophotometer (Shimadzu Co., Kyoto, Japan) over a wavelength range of $200-300 \mathrm{~nm}$, and $\lambda_{\max }$ of these compounds was estimated from the calibration curve. The binding of sorafenib drug with casein micelles was analyzed by UV spectrophotometry.

\section{Synthesis of camel milk casein nanoparticle}

Casein nanoparticles were prepared according to an earlier reported method with some modifications (Gandhi and Roy, 2018). Five percent casein solution was mixed with the drug sorafenib at a concentration of $200 \mu \mathrm{g} / \mathrm{mL}$ and was stirred at $900 \mathrm{rpm}$ at room temperature for $1 \mathrm{~h}$. This was followed by the addition of $50 \mu \mathrm{L}(10 \mathrm{mM}) \mathrm{CaCl}_{2}$ until the solution became turbid. This same has been explained pictorially in Fig. 1.

\section{Characterization of camel milk casein nanoparticle}

\section{FTIR study}

The physical compatibility between casein nanoparticles and sorafenib was investigated by FTIR spectroscopy. Briefly, the spectra of casein, sorafenib, their mixture (1:1), and sorafenib loaded casein nanoparticles were recorded using a Fourier Transformed-IR system (Alpha Bruker's) equipped with a germanium attenuated total reflection (ATR) system. Lyophilized Solid samples of each were placed directly in the FT-IR sample holder in direct contact with the ATR 


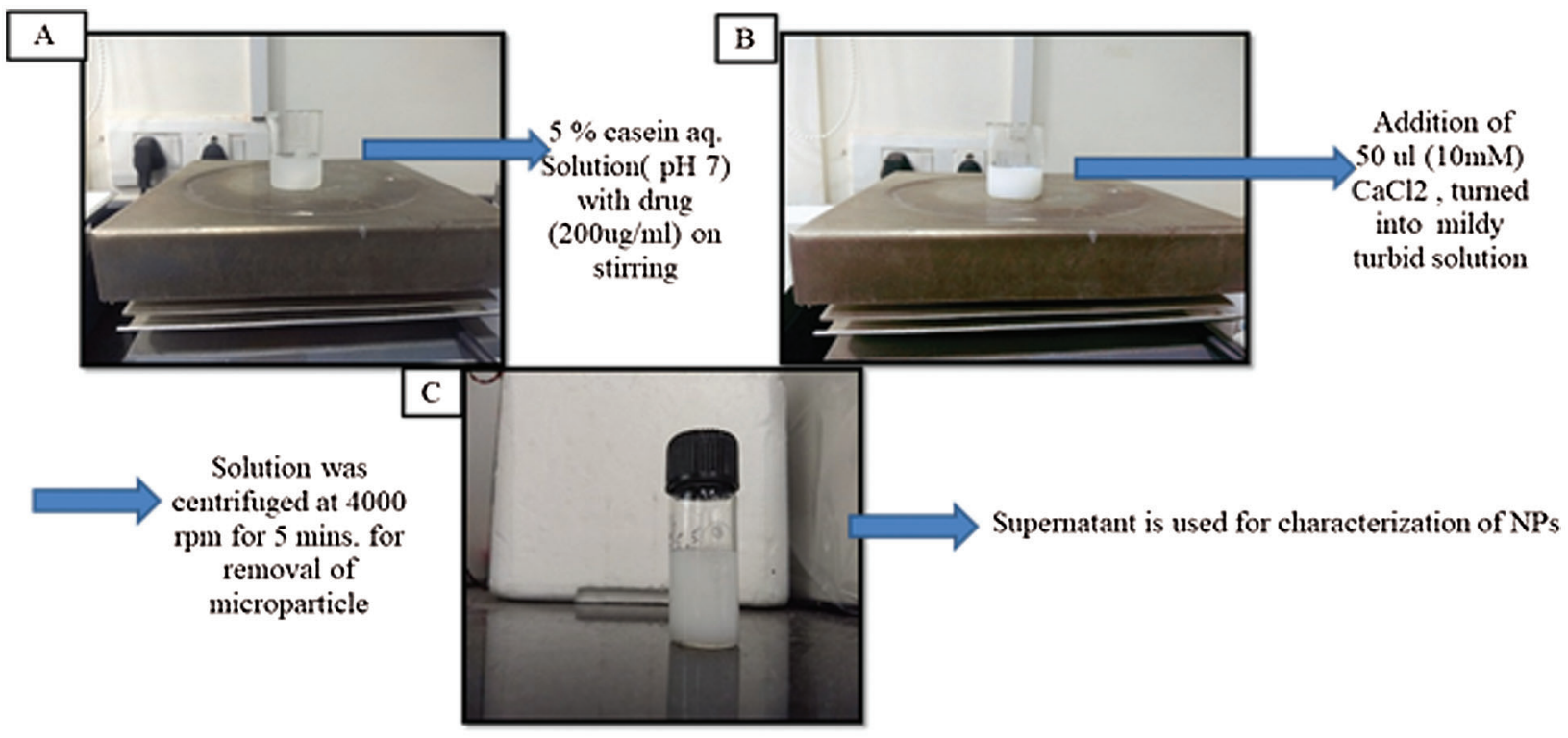

FIGURE 1. Pictorial representation of the synthesis of casein nanoparticles. (A) $5 \%$ casein solution with sorafenib drug. (B) Turbid mildly casein solution upon addition of calcium chloride $\left(\mathrm{CaCl}_{2}\right)$. (C) Casein nanoparticle.

crystal. IR spectra were obtained in the spectral region $4,000 \mathrm{~cm}^{-1}$ to $500 \mathrm{~cm}^{-1}$, in transmittance mode.

Physical property analysis and scanning electron microscopy of camel milk casein nanoparticles

The prepared casein nanoparticles were characterized for the size, polydispersity index (PDI), and zeta potential using a Zetasizer, Nano series (Nano-ZS, Malvern, UK). The casein nanoparticle diameter and surface charge/ZP were measured in water $\mathrm{pH}(6.2-7.4)$ at $25^{\circ} \mathrm{C}$ with a scattering angle of $90^{\circ} \mathrm{C}$. Morphology was examined by scanning electron microscopy (SEM) at a voltage of $20 \mathrm{kV}$ after coating with gold under vacuum. Drops of Nanoparticles samples were put on slides and were dried under nitrogen gas. Then these slides were placed on aluminum stubs fixed by double-sided tape and placed in the vacuum chamber of SEM (Thermo Scientific $^{\text {TM }}$ Apreo scanning electron microscope). Slides were seen from $30,000 \times$ to $10,000 \times$ magnifications.

\section{Drug encapsulation efficiency}

To quantify the drug content, $1 \mathrm{~mL}$ aliquot of the nanoparticle solution containing the drug was centrifuged at $10,000 \mathrm{rpm}$ for $20 \mathrm{~min}$ at $4^{\circ} \mathrm{C}$. Now the pellet was dissolved in methanol to precipitate the protein. Subsequently, it was vortexed for $1 \mathrm{~h}$, followed by centrifugation at $6000 \mathrm{rpm}$ for $10 \mathrm{~min}$. The drug concentration in the pellet was determined using a UV spectrophotometer. Results have been presented as means \pm SE of three independent experiments, each performed in duplicate. The encapsulation efficiency (E.E.) was calculated by using the following formula:

E.E. $(\%)=($ mass of a drug in nanoparticles/mass of drug used in formulation) $\times 100$.

\section{Cell culture associated studies}

Culture of cells

HepG 2 cells procured from NCCS, Pune, India, were cultured at $37^{\circ} \mathrm{C}, 5 \% \mathrm{CO}_{2}$, in minimum essential medium (Invitrogen) supplemented with $10 \%$ fetal bovine serum (Invitrogen) and $1 \%$ antibiotics solution-Penicillin (100 $\left.\mathrm{U}_{\mathrm{mL}}^{-1}\right)$ and streptomycin (100 $\mu \mathrm{g} \mathrm{mL} \mathrm{m}^{-1}$; Invitrogen). Trypsin-EDTA solution $(0.05 \%)$ was used for the detachment of cells. The cells were grown to $70 \%$ confluence in tissue culture flasks (Tarson), detached using Trypsin EDTA solution, rinsed in phosphate buffer saline, and finally transferred in complete fresh medium. Subsequently, they were analyzed for cellular uptake, viability, and morphological changes.

\section{Cellular internalization study}

Coumarin-6 (green-fluorescent dye) entrapped casein nanoparticles were prepared in the same way as described above in synthesis part. HepG2 cells were seeded on coverslips in six-well plates and treated with the $3 \mu \mathrm{g} / \mathrm{mL}$ of coumarin- 6 entrapped casein nanoparticles at $37^{\circ} \mathrm{C}$ for 4 and $6 \mathrm{~h}$, respectively. The cells were then washed twice with PBS to remove nanoparticles not taken up by the cells and fixed with methanol for $10 \mathrm{~min}$. Subsequently, they were stained with DAPI $(2 \mu \mathrm{g} / \mathrm{mL})$ for 3-5 min and washed twice with PBS. Cells were mounted using glycerol and examined under a fluorescence microscope (Zeiss Axio Scope A1) using the filters for DAPI and FITC. The merged image was also obtained for better visualization.

\section{Cytotoxicity assay}

MTT (3-(4, 5-dimethylthiazol-2-yl)-2,5-diphenyltetrazolium Bromide) assay was used to determine the cytotoxicity of the drug, sorafenib, and its loaded casein nanoparticles. Briefly, HepG2 cells were seeded at a density of 8000 cells/well in a 96-well plate. After reaching the $70 \%$ confluence, cells were treated with different concentrations of the drug sorafenib and its loaded casein nanoparticles for $24 \mathrm{~h}$. MTT was added to cells and incubated for $4 \mathrm{~h}$ at $37^{\circ} \mathrm{C}$. Subsequently, the media was discarded and $150 \mu \mathrm{L}$ of DMSO was added to each well. The color intensity was measured at $570 \mathrm{~nm}$ wavelength, using a microplate reader Multiskan $^{\mathrm{TM}}$ Thermo Scientific ${ }^{\mathrm{TM}}$ ). Each determination was 
carried out in triplicate and at least two independent experiments were carried out. Cell viability was calculated as using the following formula:

$\%$ Cell viability $=\mathrm{OD}$ of treated cells $/ \mathrm{OD}$ of control (without treatment) $\times 100$

\section{DAPI staining}

HepG2 cells were implanted on a coverslip in a 6-well plate and incubated with only sorafenib and casein encapsulated sorafenib, respectively, at $10 \mu \mathrm{M}$ and $20 \mu \mathrm{M}$ concentration for $24 \mathrm{~h}$. Cells were then washed twice with PBS, fixed with ice-cold methanol, and again washed twice with PBS. Next, cells were stained with DAPI $(2 \mu \mathrm{g} / \mathrm{mL})$ and incubated for $10 \mathrm{~min}$ at room temperature in the dark. The cells were finally washed with PBS two times and visualized under a fluorescence microscope (ZEISS Axio Scope A1 microscope). The Apoptotic bodies were observed.

\section{Statistical Analysis}

Graphs and statistical analysis of data was performed by using GraphPad prism5 software. The data are given as the mean values \pm SEM. Comparisons among inter and intra groups were analyzed using one-way and two-way ANOVA followed by the Bonferroni post test. $P<0.05$ was considered to indicate a statistically significant difference. All experiments were repeated at least three times performed in triplicates.

\section{Result and Discussion}

Solubility and SDS PAGE analysis of camel milk casein protein Camel milk casein was obtained at its isoelectric $\mathrm{pH}$, i.e., 4.6 at room temperature. It is a hydrophobic protein, insoluble in water. At high $\mathrm{pH}$ (7, 9 and 12), casein will have a net negative charge (due to ionization of its acidic side chains); therefore, it was soluble after the addition of $1 \mathrm{~N} \mathrm{NaOH}$ (sodium hydroxide) at all the three $\mathrm{pH}$ values, as shown in Fig. 2A. Camel milk casein is a major dietary phosphoprotein, which is of 4 types, namely, as1 casein, as2 casein, $\beta$ casein, and $k$ casein. The electrophoretic migration of camel milk casein has been depicted in Fig. $2 \mathrm{~B}$ at the three different $\mathrm{pH}$ studied. The molecular weight of $\alpha$-caseins, $\beta$-casein, and $k$-casein was observed to be about $28 \mathrm{kDa}, 26 \mathrm{kDa}$, and $22 \mathrm{kDa}$, respectively, at each $\mathrm{pH}$ as expected and reported earlier (Yelubaeva et al., 2017; Kappeler et al., 1999). It was also clearly seen that the bands which correspond to whey protein in camel skimmed milk are decreased or disappeared in casein protein, depicting the relative purity of the isolated casein protein.

\section{$U V$-visible spectroscopic analysis}

Spectrum analysisof the drug sorafenib, camel milk casein, and the drug mixed with casein (not as nanoparticle) was determined by UV spectroscopy, and the respective $\lambda_{\max }$ was determined and shown in Fig. 3. Casein $(1 \mu \mathrm{g} / \mathrm{mL})$ exhibits maximum absorption at the wavelength of $275 \mathrm{~nm}$, as shown in Fig. 3A. It can be explained by the presence of the aromatic side-chains of amino acids like tryptophan (Trp), tyrosine (Tyr), and phenylalanine (Phe) residues which absorb in this range of wavelength (Goldfarb et al., 1951; Antosiewicz and Shugar, 2016). Sorafenib showed maximum absorbance at $264 \mathrm{~nm}$ at all the concentrations studied, ranging from $1-6 \mu \mathrm{g} / \mathrm{mL}$. This corresponds to earlier studies (Onur, 2018) and has been shown in Fig. 3B. To investigate the effect of sorafenib interaction with camel milk casein for any structural changes induced mixture, the UV spectrum of casein was plotted taking various concentrations of sorafenib (Fig. 3C). The maximum absorption peak of casein alone was at $275 \mathrm{~nm}$, and it remained unchanged in the presence of sorafenib at the concentration range studied. With the increase in sorafenib concentration, the absorbance of casein gradually increased from 0.6 to 0.9 at the same $\lambda_{\max }(275 \mathrm{~nm})$. This suggests that the polarity of the microenvironment around Trp and Tyr residues of casein has been changed by the drug, but this does not cause its conformational change in casein (Li et al., 2011; Yue et al., 2012). The linear calibration curve obtained on measuring the absorbance of the sorafenib at various concentrations has been shown in Fig. 3D, which has good linearity with a correlation coefficient of $\mathrm{R}^{2}=0.998$.

\section{Synthesis of camel casein nanoparticle}

In this study, we have indigenously prepared novel camel milk casein nanoparticles and have explored their use as a carrier for the anticancer drug sorafenib. Casein self-assembles into spherical micelles at $\mathrm{pH} 7$ when dissolved in water, and sorafenib gets encapsulated into the hydrophobic core of casein micelles (Corzo-Martínez et al., 2015). This is further
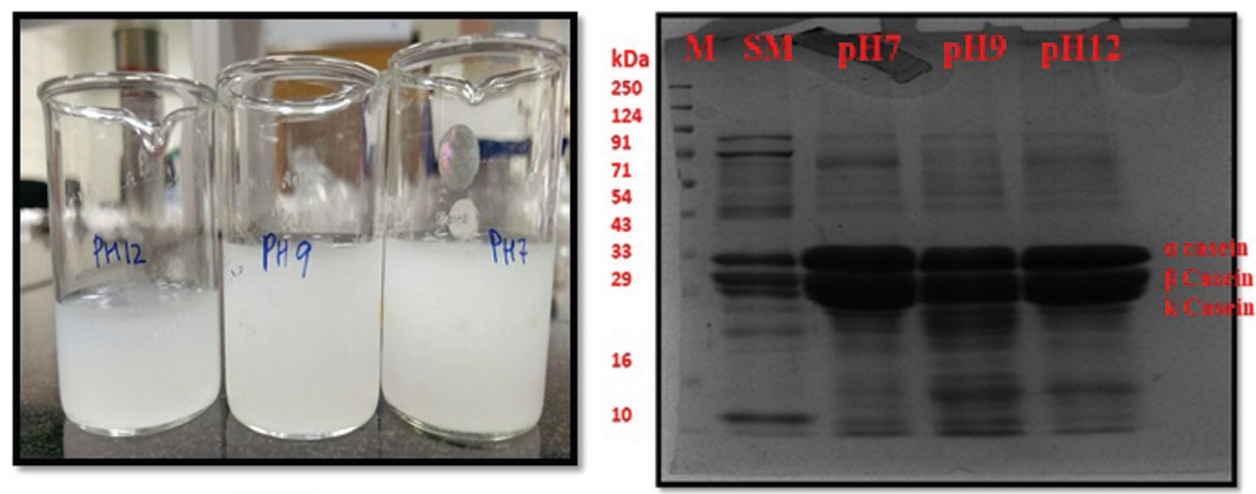

A
FIGURE 2. (A) Solubilization of camel milk casein solution at $\mathrm{pH} 7$, 9, and 12. (B) SDS-PAGE image of solubilized casein at $\mathrm{pH} 7,9$, and 12. The molecular weight marker has been loaded in the $1^{\text {st }}$ lane, skimmed camel milk (SM) in the $2^{\text {nd }}$ lane, and camel milk casein at $\mathrm{pH} 7,9$, and 12 have been loaded in lanes 3, 4, and 5, respectively. 

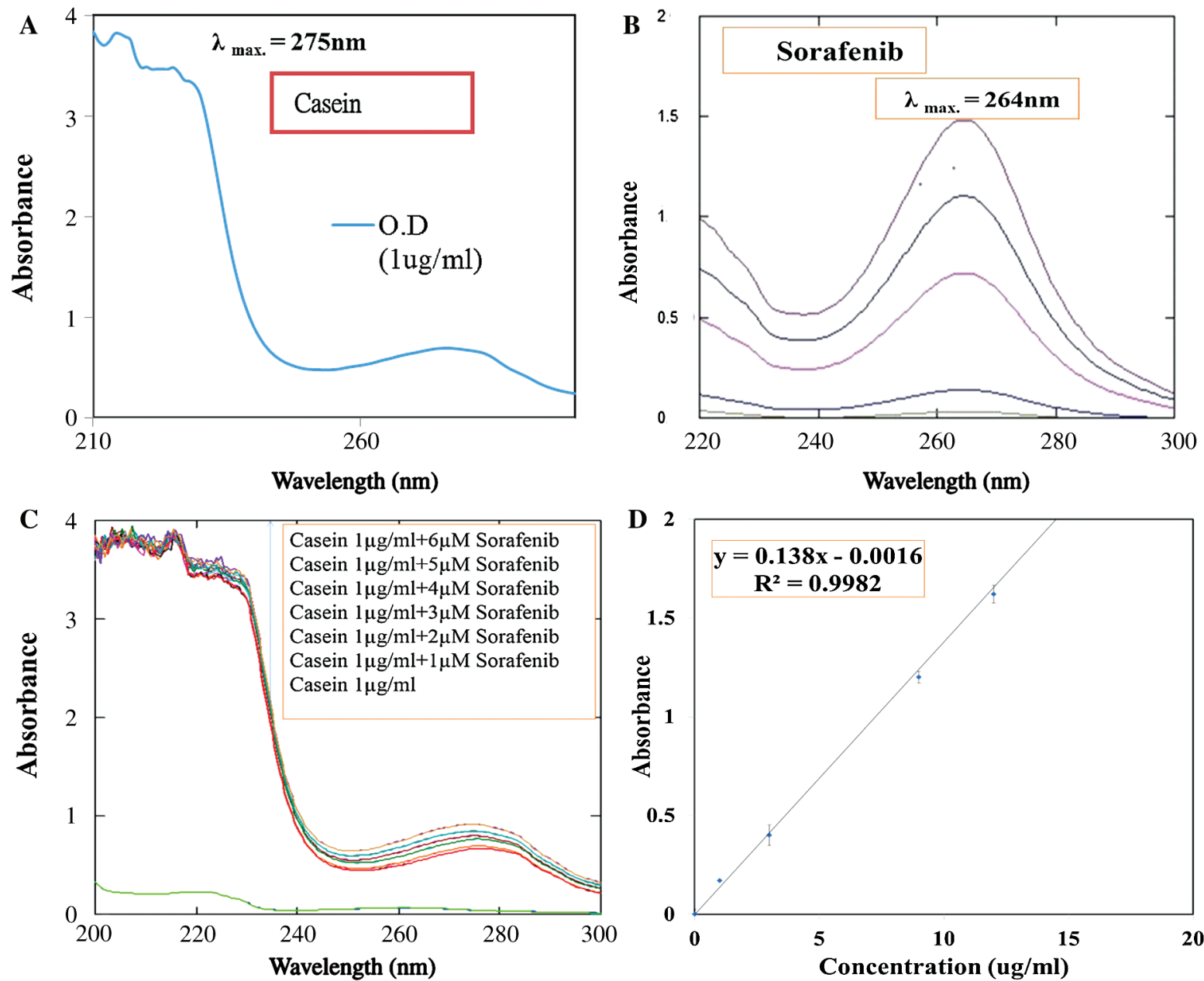

FIGURE 3. UV-Visible spectrum. (A) UV spectra of camel casein protein. (B) UV spectra of sorafenib at various dilutions. (C) UV spectra of casein $(1 \mu \mathrm{M})$ in the absence and presence of different concentrations of Sorafenib drug (1-6 $\mu \mathrm{M})$. (D) Calibration curve of sorafenib drug.

stabilized by the addition of calcium chloride solution, which also maintains the micellar integrity (Sosa-Herrera et al., 2012). The solution formed was mildly turbid due to the presence of densely formed casein nanoparticles (Penalva et al., 2015). Pictorial depiction of synthesis of nanoparticle done by us has been described earlier in Fig. 1, and its features are described subsequently. No exogenous crosslinkers and toxic chemicals were used in the process of preparation.

\section{Characterization of camel milk casein nanoparticle}

\section{FTIR spectra analysis}

The chemical analysis of the drug casein, physical mixture of casein, and drug, as well as the drug-loaded casein nanoparticle, was subjected to analysis by FTIR spectroscopy, as shown in Fig. 4. The mixture was also used in order to investigate any possible chemical association, change in composition, or compatibility between the drug and its carrier. The initial peaks higher than $3608 \mathrm{~cm}^{-1}$ are due to the solvent system in all four panels. The uppermost panel represents the sorafenib peak. The peaks at $3062 \mathrm{~cm}^{-1}$ and $2928 \mathrm{~cm}^{-1}$ (due to the $\mathrm{C}-\mathrm{H}$ stretching band of aromatic and aliphatic $\mathrm{CH}$, respectively) are evident. The sorafenib peak at $1696.4 \mathrm{~cm}^{-1}$ is characteristic of the amide group $(\mathrm{C}=\mathrm{O})$. Absorption peaks of casein $\left(2^{\text {nd }}\right.$ panel from top $)$ are at $3273 \mathrm{~cm}^{-1}$ (amide band) and at $1639 \mathrm{~cm}^{-1}$, which is mainly associated with the $\mathrm{C}=\mathrm{O}$ stretching vibration and depends on the backbone conformation and hydrogen bonding. Casein also exhibits another characteristic band at $1442 \mathrm{~cm}^{-1}$ which may be attributed to the carboxylate group (O-C-O). The major absorption peaks shown in casein and drug spectra were also found in their physical mixture spectrum ( $3^{\text {rd }}$ panel from the top) and casein loaded nanoparticle ( $4^{\text {th }}$ panel from the top). FTIR spectral analysis as conducted by us revealed that the specific functional groups of casein as a carrier and the drug sorafenib in the nanoparticles have almost identical chemical characteristics of the pure casein and drug bound together. This indicates that there was not any significant chemical bonding between the two molecules, i.e., sorafenib was well encapsulated within casein nanoparticles. This is in line with the spectrometric analysis done earlier in above Fig. 3.

Physical and morphological studies of unloaded and drug loaded camel casein nanoparticles

The novel camel casein nanoparticles were analyzed to determine their particle size, distribution, and zeta potential 


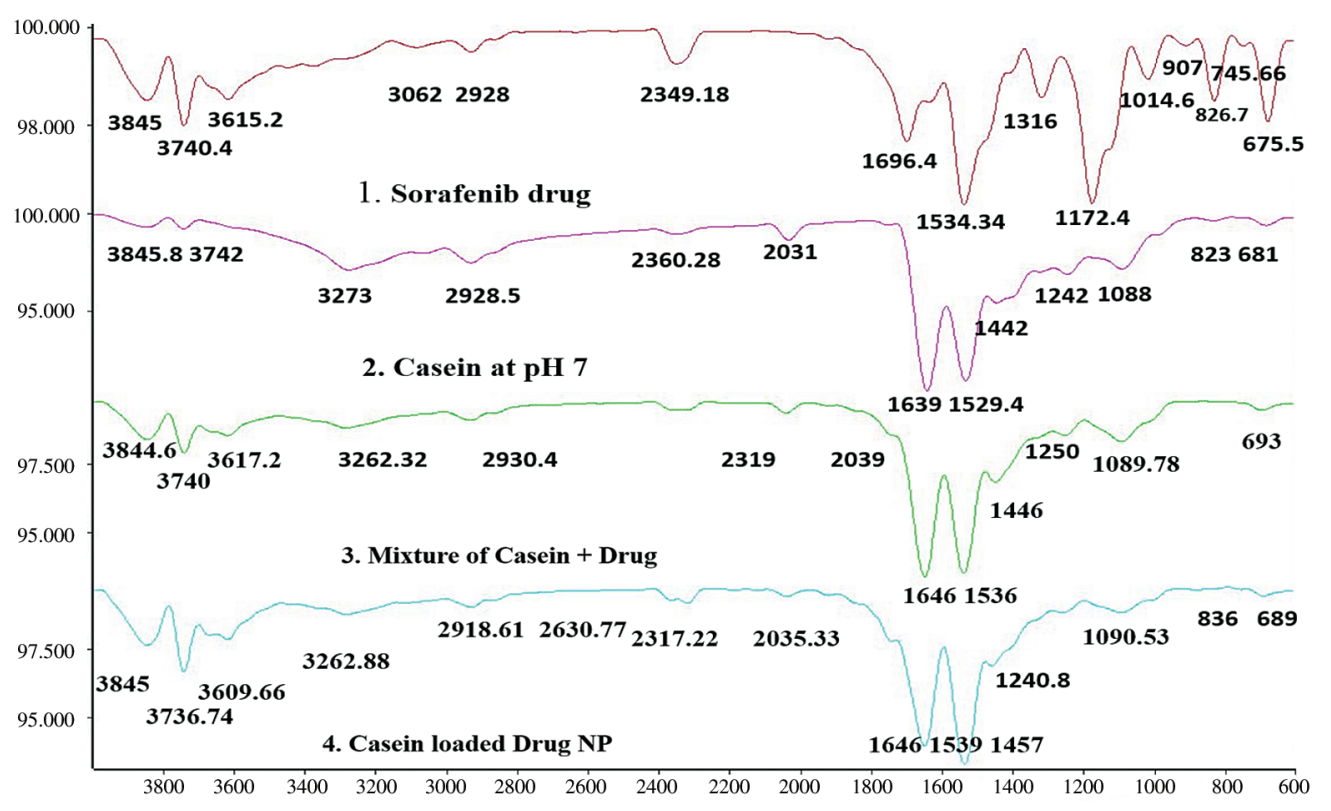

FIGURE 4. FTIR spectra of (1) sorafenib drug, (2) casein at $\mathrm{pH}$ 7, (3) a physical mixture of casein and drug, and (4) caseinloaded drug nanoparticle (NP). using the Malvern zeta sizer, shown in Fig. 5 and Tab. 1. Camel milk casein nanoparticles were found to have an average hydrodynamic particle size of $192 \pm 5.4 \mathrm{~nm}$ with a polydispersity index of 0.22 , whereas sorafenib-loaded camel casein nanoparticles had a slightly greater size, i.e., $212 \pm 6$ $\mathrm{nm}$, with a narrow polydispersity index of 0.23 (shown in Tab. 1). This indicates that the particles were uniform and monodispersed. The entrapment efficiency of drug-loaded nanoparticles was observed to be $51.5 \pm 3.2 \%$. Zeta potential is the measure of the surface charge of NPs and has an important effect on the stability of the colloidal system. The zeta potential of casein nanoparticles was found to be negatively charged (data are shown in Tab. 1) because of the ionized carboxylic groups of sodium caseinate at $\mathrm{pH}$ 7. The negative surface charge is also indicative of low toxicity as compared to the positively charged nanoparticle, which internalizes the cells by various mechanisms that need to be explored further (Tang et al., 2018).

The shape of camel casein nanoparticles was analyzed using scanning electron microscopy (SEM). A smooth surface and spherical shape of the nanoparticles were observed as has been shown in Fig. 6. The size of particles ranges between $160-220 \mathrm{~nm}$, which is in agreement with the dynamic light scattering studies done earlier (Penalva et al., 2015).

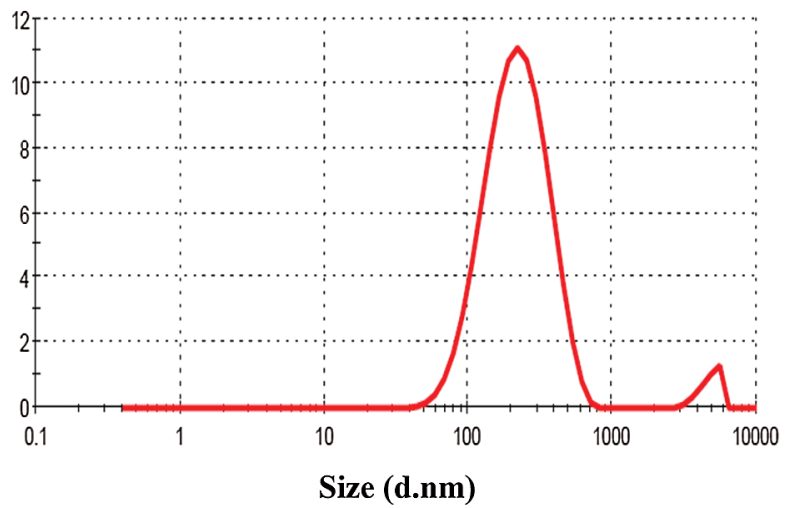

A

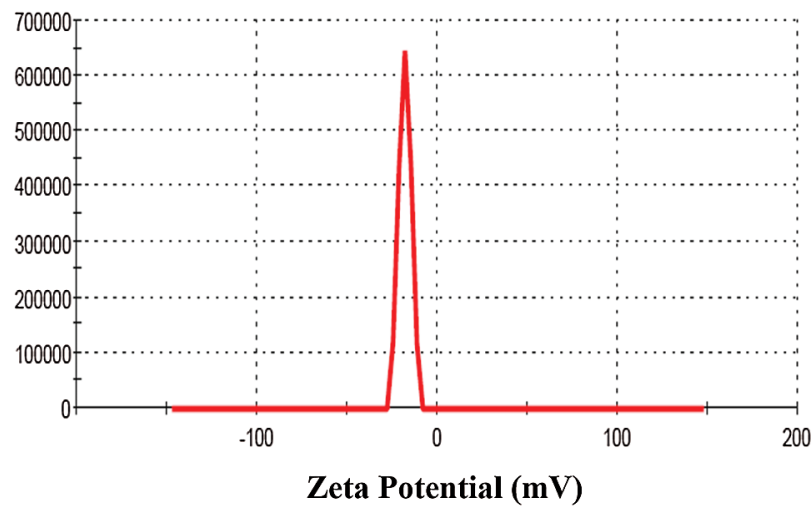

B

FIGURE 5. Measurement of nanoparticles. (A) Size and (B) zeta potential of casein nanoparticles by dynamic light scattering (DLS).

TABLE 1

Characterization of nanoparticles

\begin{tabular}{lllll}
\hline NPs & $\mathbf{D}_{\mathbf{h}}(\mathbf{n m})$ & PDI & ZP $(\mathbf{m V})$ & EE\% \\
\hline Casein NP & $192 \pm 5.4$ & 0.21 & $-23 \pm 1.5$ & - \\
Sorafenib loaded casein nanoparticle & $212 \pm 6$ & 0.22 & $-20 \pm 1.2$ & $51.5 \pm 3.2$ \\
\hline
\end{tabular}

Note: $\mathrm{D}_{\mathrm{h}}$, average hydrodynamic diameter; PDI, polydispersity index; ZP, zeta potential; EE, drug encapsulation efficiency. Data represent mean $\pm \mathrm{SD}(\mathrm{N}=3)$. 


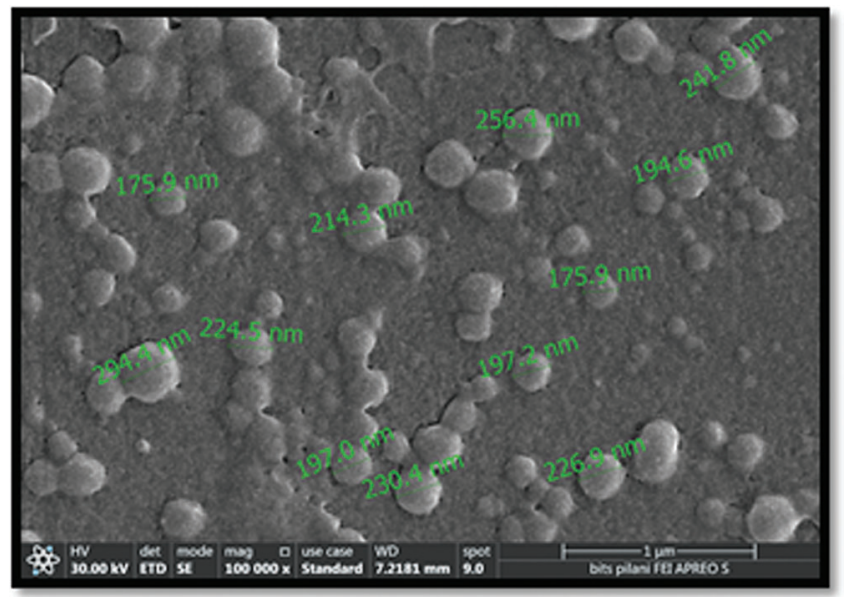

FIGURE 6. Scanning electron microscopic image of camel casein nanoparticles.

\section{Cellular internalization study}

Coumarin-6 encapsulated casein nanoparticle was used to study cellular uptake as it serves as a suitable fluorescent probe. The resulting fluorescence images depict that coumarin- 6 dye-loaded nanoparticles were effectively taken up by the cells (Fig. 7). Coumarin-6 dye-loaded nanoparticles showed a preferentially higher accumulation in the cytoplasm as compared to the nucleus of HepG2 cells (after $4 \mathrm{~h}$ and $6 \mathrm{~h}$ of incubation), as compared to the only dye-treated cells. It can also be seen that the fluorescent intensity of Coumarin- 6 encapsulated casein nanoparticles also increased within $2 \mathrm{~h}$ (between $4 \mathrm{~h}$ and $6 \mathrm{~h}$ ) of the time interval. This enhanced cellular internalization associated with the nanoparticles could translate to better therapeutic efficacy.

\section{Cellular toxicity study}

Cytotoxicity of our novel drug-loaded casein nanoparticles was evaluated in the HepG2 cell line by the MTT assay after
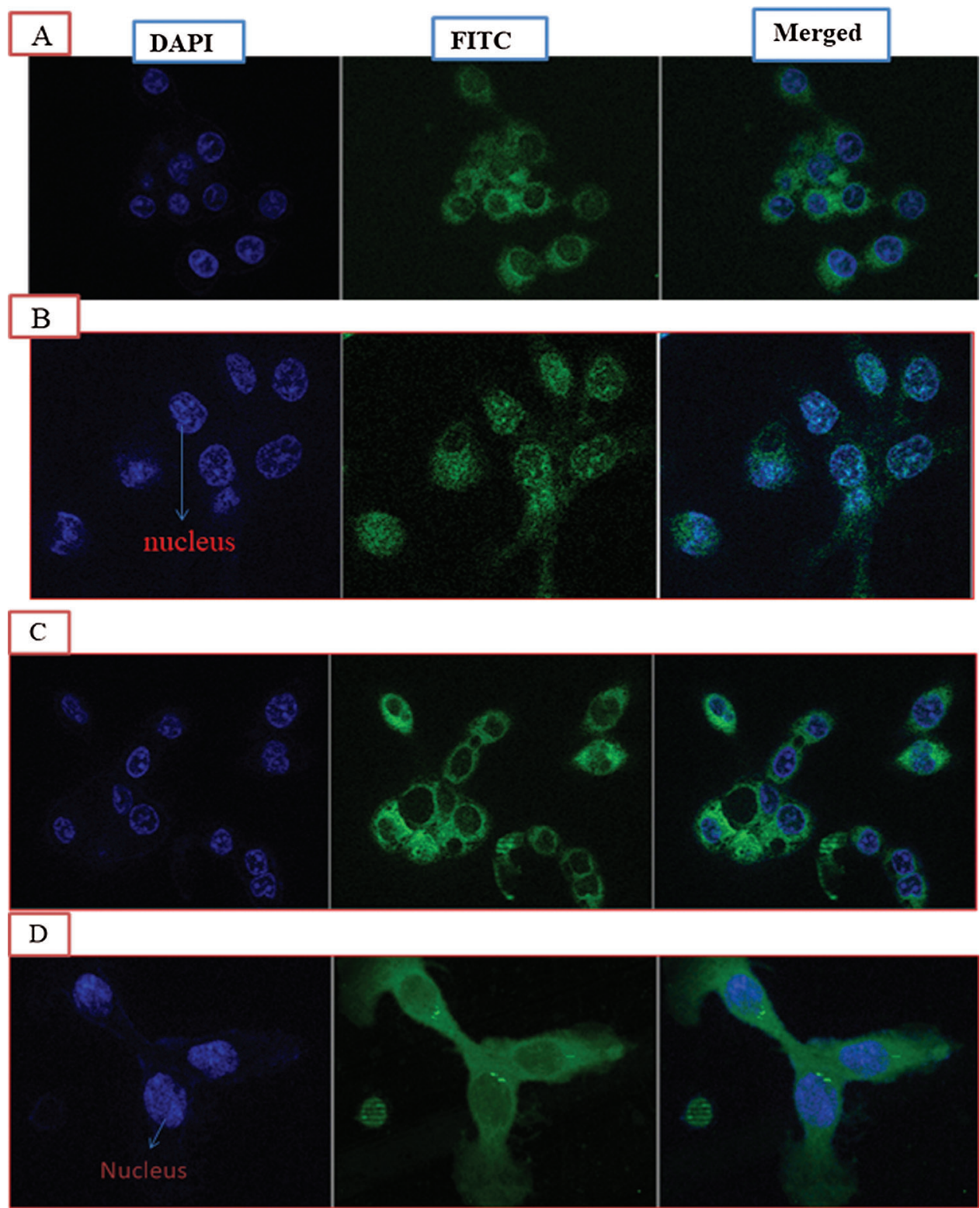

FIGURE 7. Internalization study of fluorescent dye (coumarin)-loaded casein nanoparticle by fluorescence microscopy on HepG2 cells. (A) Fluorescent images of HepG2 cells after $4 \mathrm{~h}$ incubation with coumarin-loaded casein nanoparticle. (B) HepG2 cells after $4 \mathrm{~h}$ incubation with free coumarin. (C) Fluorescent images of HepG2 cells after 6 h incubation with coumarin-loaded casein nanoparticle. (D) HepG2 cells after 6 h incubation with free coumarin. 


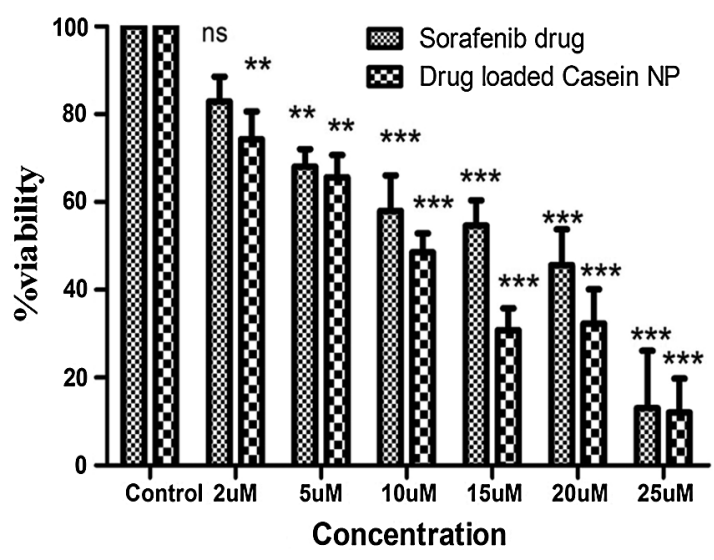

FIGURE 8. Cell viability of HepG2 cells treated with Sorafenib loaded casein nanoparticle and free Sorafenib. The data are given as the mean values \pm SEM. ${ }^{\star *} P<0.01,{ }^{* *} P<0.001$, ns $=$ non-significant.
A
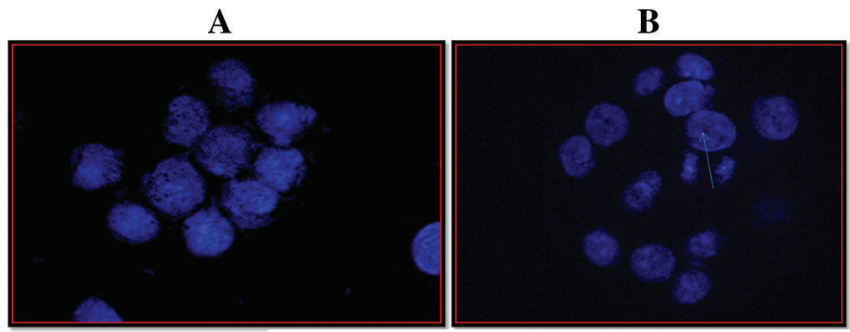

D

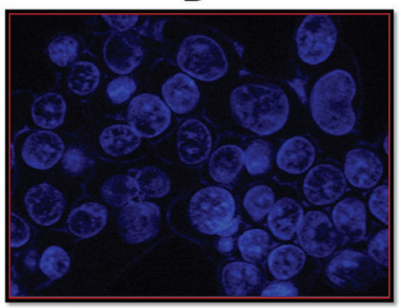

C

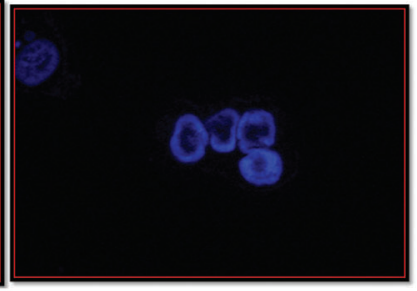

E

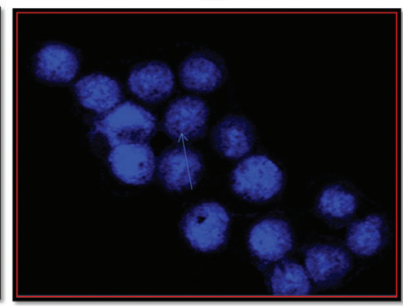

FIGURE 9. Fluorescence images of DAPI stained HepG2 cells treated with drug-loaded casein nanoparticle and only drug sorafenib. Magnification $60 \times$. (A) Control cells without any treatment. (B) Cells treated with sorafenib loaded casein $\mathrm{np}$ (conc. $10 \mu \mathrm{m})$. (C) Cells treated with sorafenib loaded casein $\mathrm{np}$ (conc. $20 \mu \mathrm{m})$. (D) Cells treated with sorafenib (conc. $10 \mu \mathrm{m}$ ). (E) Cells treated with sorafenib (conc. $20 \mu \mathrm{m})$
$24 \mathrm{~h}$. Improved cytotoxic efficacy of sorafenib in HepG2 cell line in-vitro, was observed as compared to the untreated control, as has been shown in Fig. 8. According to the results, the $\mathrm{IC}_{50}$ concentrations were determined as $\sim 15 \mu \mathrm{M}$ for sorafenib and $\sim 10 \mu \mathrm{M}$ for sorafenib loaded casein NPs, respectively. Sorafenib-loaded casein NPs had a remarkable activity on HepG2 cells at $10 \mu \mathrm{M}$ concentration $(48.5 \%$ cell viability), whereas it has been observed that when treated with non-encapsulated sorafenib there was $(58 \%$ cell viability) at the same concentration. This can be due to better internalization of drug-loaded nanoparticles into the cells as compared to the only drug. Further, it was observed that the cytotoxicity increased with increasing concentration of drug in a statistically significant manner.

To gain further insight into the mechanism involved, the cells were stained with DAPI, a nuclear stain. Cell shrinkage, nuclear fragmentation, and margination of the nucleus were observed in cells after treatment with the drug-loaded casein nanoparticle as well as with only sorafenib, as can be observed in Fig. 9. In untreated control cells, the nucleus was seen as normal without any condensation of nuclear material.

\section{Conclusion}

In the present study, novel camel milk casein nanoparticles were developed by us and loaded with the drug sorafenib to overcome its poor solubility and bioavailability. We have successfully developed the camel milk casein nanoparticles with a particle size of around $200 \mathrm{~nm}$ with a uniform spherical shape and negative charge. This drug-loaded nanoparticle had higher intracellular uptake of sorafenib as compared to the uptake of the only drug. The drug-loaded nanoparticles were found more cytotoxic and induced apoptosis in the mammalian hepatocarcinoma cell line, HepG2. In the future, the focus on in vivo pharmacokinetic studies of this developed anticancer drug delivery system is of high relevance.

Acknowledgement: We thank our institute BITS Pilani for providing all the logistic and infrastructural support for conducting thiswork. We also thank Raika Milk Bhandhar for providing fresh camel milk samples.

Availability of Data and Materials: All data generated or analyzed during this study are included in this published article.

Author Contribution: The authors confirm contribution to the paper as follows: Study conception and design: Uma S. Dubey, Sunil K Dubey. data collection: Aastha Mittal and Neelam Mahala, analysis and interpretation of results: Aastha Mittal and Krishna.V; draft manuscript preparation: Aastha, Sunil K Dubey, Uma S. Dubey. All authors reviewed the results and approved the final version of the manuscript. 
Ethics Approval: No specific approval was required for this study.

Funding Statement: The authors received no specific funding for this study.

Conflicts of Interest: The authors declare that they have no conflicts of interest.

\section{References}

Al haj OA, Al Kanhal HA (2010). Compositional, technological and nutritional aspects of dromedary camel milk. International Dairy Journal 20: 811-821. DOI 10.1016/j.idairyj.2010.04.003.

Antosiewicz JM, Shugar D (2016). UV-Vis spectroscopy of tyrosine side-groups in studies of protein structure. Part 2: Selected applications. Biophysical Reviews 8: 163-177. DOI 10.1007/ s12551-016-0197-7.

Atri MS, Saboury AA, Moosavi-Movahedi AA, Goliaei B, Sefidbakht $\mathrm{Y}$ et al. (2011). Structure and stability analysis of cytotoxic complex of camel $\alpha$-lactalbumin and unsaturated fatty acids produced at high temperature. Journal of Biomolecular Structure and Dynamics 28: 919-928. DOI 10.1080/ 07391102.2011.10508618.

Babos G, Biró E, Meiczinger M, Feczkó T (2018). Dual drug delivery of sorafenib and doxorubicin from PLGA and PEG-PLGA polymeric nanoparticles. Polymers 10: 1-12. DOI 10.3390/ polym 10080895.

Balogh J, Victor III D, Asham EH, Burroughs SG, Boktour M (2016). Hepatocellular carcinoma: A review. Journal of Hepatocellular Carcinoma 3: 41-53. DOI 10.2147/JHC.S61146.

Corzo-Martínez M, Mohan M, Dunlap J, Harte F (2015). Effect of ultra-high pressure homogenization on the interaction between bovine casein micelles and ritonavir. Pharmaceutical Research 32: 1055-1071. DOI 10.1007/ s11095-014-1518-9.

Din FU, Aman W, Ullah I, Qureshi OS, Mustapha O, Shafique S, Zeb A (2017). effective use of nanocarriers as drug delivery systems for treatment of selected tumors. International Journal of Nanomedicine 12: 7291-7309. DOI 10.2147/IJN. S146315.

Dubey US, Lal M, Mittal A, Kapur S (2016). Therapeutic potential of camel milk. Emirates Journal of Food and Agriculture 28: 164-176. DOI 10.975/ejfa.2015-04-122.

Esmaili M, Ghaffari SM, Moosavi-Movahedi Z, Atri MS, Sharifizadeh A et al. (2011). Beta casein-micelle as a nano vehicle for solubility enhancement of curcumin; food industry application. LWT-Food Science and Technology 44: 21662172. DOI 10.1016/j.lwt.2011.05.023.

Gandhi S, Roy I (2018). Doxorubicin-loaded casein nanoparticles for drug delivery: Preparation, characterization and in vitro evaluation. International Journal of Biological Macromolecules 121: 6-12.

Głąb TK, Boratyński J (2017). Potential of casein as a carrier for biologically active agents. Topics in Current Chemistry 375: 1-20. DOI 10.1007/s41061-017-0158-z.

Gmeiner WH, Ghosh S (2015). Nanotechnology for cancer treatment. Nanotechnology Reviews 3: 111-122. DOI 10.1515/ntrev-2013-0013.

Goldfarb AR, Saidel LJ, Moscovich E (1951). The ultraviolet absorption spectra of proteins. Journal of Biological Chemistry 193: 397-404.

Hejmady S, Pradhan R, Alexander A, Agrawal M, Singhvi G et al. (2020). Recent advances in targeted nanomedicine as promising antitumor therapeutics. Drug Discovery Today 25: 2227-2244. DOI 10.1016/j.drudis.2020.09.031.
Jindal A, Thadi A, Shailubhai K (2019). Hepatocellular carcinoma: Etiology and current and future drugs. Journal of Clinical and Experimental Hepatology 9: 221-232. DOI 10.1016/j. jceh.2019.01.004.

Kappeler S, Farah Z, Puhan Z (1999). Sequence analysis of Camelus dromedarius milk caseins. InterJournal of Dairy Research 9: 481-486. DOI 10.1017/S0022029997002847.

Krishna KV, Saha RN, Dubey SK (2020). Biophysical, biochemical, and behavioral implications of ApoE3 conjugated donepezil nanomedicine in a A $\beta 1-42$ induced Alzheimer's disease rat model. ACS Chemical Neuroscience 11: 4139-4151. DOI 10.1021/acschemneuro.0c00430.

Krishna KV, Wadhwa G, Alexander A, Kanojia N, Saha RN et al. (2019). Design and biological evaluation of lipoproteinbased donepezil nanocarrier for enhanced brain uptake through oral delivery. ACS Chemical Neuroscience 10: 4124-4135. DOI 10.1021/acschemneuro.9b00343.

Krishna KV, Dubey SK, Singhvi G, Gupta G, Kesharwani P (2021). MAPK pathway: Potential role in glioblastoma multiformurgery. Interdisciplinary Neurosurgery: Advanced Techniques and Case Management 23: 100901. DOI 10.1016/j.inat.2020.100901.

Kumar D, Chatli MK, Singh R, Mehta N, Kumar P (2016). Enzymatic hydrolysis of camel milk casein and its antioxidant properties. Dairy Science and Technology 96: 391-404. DOI 10.1007/s13594-015-0275-9.

Li D, Zhu M, Xu C, Ji B (2011). Characterization of the baicalein ebovine serum albumin complex without or with $\mathrm{Cu}^{2+}$ or $\mathrm{Fe}^{3+}$ by spectroscopic approaches. European Journal of Medicinal Chemistry 46: 588-599. DOI 10.1016/j.ejmech.2010.11.038.

Lohcharoenkal W, Wang L, Chen YC, Rojanasakul Y (2014). Protein nanoparticles as drug delivery carriers for cancer therapy. BioMed Research International 2014: 180549. DOI 10.1155/ 2014/180549.

Madadlou A, Mousavi ME, Emam-Djomeh Z, Sheehan D, Ehsani M (2009). Alkaline $\mathrm{pH}$ does not disrupt re-assembled casein micelles. Food Chemistry 116: 929-932. DOI 10.1016/j. foodchem.2009.03.04.

Onur S (2018). Rapid determination and validation of sorafenib via uv-visible method in pharmaceutical formulations. Balıkesir Sağlik Bilimleri Dergisi 7: 87-92.

Patra JK, Das G, Fraceto LF, Vangelie E, Campos R et al. (2018). Nano based drug delivery systems: Recent developments and future prospects. Journal of Nanobiotechnology 16: 1-33. DOI 10.1186/s12951-018-0392-8.

Penalva R, Esparza I, Agüeros M, Gonzalez-Navarro CJ, GonzalezFerrero C, Irache JM (2015). Casein nanoparticles as carriers for the oral delivery of folic acid. Food Hydrocolloids 44: 399-406.

Sahu A, Kasoju N, Bora U (2008). Fluorescence study of the curcumin-casein micelle complexation and its application as a drug nanocarrier to cancer cells. Biomacromolecules 9: 2905-2912.

Salami M, Moosavi-Movahedi AA, Moosavi-Movahedi F, Ehsani MR, Yousefi R et al. (2011). Biological activity of camel milk casein following enzymatic digestion. Journal of Dairy Research 78: 471-478. DOI 10.1017/S0022029911000628.

Singh R, Lillard JW Jr (2009). Nanoparticle-based targeted drug delivery. Experimental \& Molecular Pathology 86: 215-223. DOI 10.1016/j.yexmp.2008.12.004.

Sosa-Herrera MG, Lozano-Esquivel IE, Ponce de León-Ramírez YR, Martínez-Padilla LP (2012). Effect of added calcium chloride 
on the physicochemical and rheological properties of aqueous mixtures of sodium caseinate/sodium alginate and respective oil-in-water emulsions. Food Hydrocolloids 29: 175-184. DOI 10.1016/j.foodhyd.2012.02.017.

Tang X, Chen L, Li A, Cai S, Zhang Y et al. (2018). Anti-GPC3 antibodymodified sorafenib-loaded nanoparticles significantly inhibited HepG2 hepatocellular carcinoma. Drug Delivery 25: 14841494. DOI 10.1080/10717544.2018.1477859.
Yelubaeva MY, Buralkhiev BA, Serikbayeva AD, Narmuratova MH, Kenenbay SY (2017). Electrophoretic identification of casein in various types of milk. OnLine Journal of Biological Sciences 17: 348-352.

Yue Q, Shen T, Wang C, Gao C, Liu J (2012). Study on the interaction of bovine serum albumin with ceftriaxone and the inhibition effect of zinc (II). International Journal of Spectroscopy 2012: 284173. DOI $10.1155 / 2021 / 284173$. 